УДК 141.319 .8

DOI https://doi.org/10.32837/apfs.v0i27.916

\author{
В. В. Лысенкова \\ ORCID ID: https://orcid.org/0000-0001-8227-3974 \\ доктор философских наук, доиент, \\ доцент кафедры гуманитаристики и искусствоведения \\ Харьковской государственной академии культуры
}

\title{
ФИЛОСОФСКИЕ АСПЕКТЫ ИЗУЧЕНИЯ ОБРАЗА ЖИЗНИ И. ГЕТЕ (ПО РОМАНУ Т. МАННА «ЛОТТА В ВЕЙМАРЕ»)
}

Актуальность. В силу того, что проявление гениальности стало сравнительно редким явлением, интерес к этой проблеме, возникшей в 70-е годы XX века (В. Эфроимсон) не только не утихает, но и идет по нарастающей. Изучение различных аспектов гениальности должно помочь в изучении ее природы, причин и условий появления, путей формирования гениальных людей.

В статье автор пытается выяснить, как складываются отношения гения с его ближайшим окружением, каков образ жизни деятеля мировой культуры, его роль в общественном прогрессе.

Степень изученности проблемы. Литература о творчестве И. Гете обширна. Авторы исследовали его вклад в мировое интеллектуальное наследие с различных позиций. Весомые разработки осуществили А. Авуш, Р. Бухвальд, И. Верцман, Н. Вильмонт, В. Гейзенберг, О. Гротеволь, К. Гулиан, А. Гулыга, О. Джинория, Ф. Зейдел, О. Конради, Н. Корфф, В. Кочорадзе, И. Луппол, П. Рейман, К. Свасьян, Ю. Шичалин, И. Эккерман.

Тема, заявленная в статье, прямо не рассматривалась ими, и лишь иногда ученые косвенно останавливали на ней свое внимание, чего явно недостаточно для понимания сложности жизнедеятельности гения.

Цель статьи. В тексте автор стремится отобразить непростое бытование гения в мещанской атмосфере Германии на рубеже XVIII - XIX веков, непонимание обывателями всех перипетий его мощной интеллектуальной жизни. И. Гете стремится как можно меньше тратить времени на необязательное общение, а филистерами это воспринимается как высокомерие и холодность с его стороны. Им не понять постоянное внутреннее духовное и умственное напряжение, непрерывный поиск истины, масштаб его научной и общественной деятельности.

Изложение содержания статьи. Современная генеалогия уже накопила значительный материал о специфике жизни гениев, их становлении, особенностях самореализации, отношении к окружающей действительности. Она направлена на познание проблем сущности, характера, механизмов деятельности гениев и их жизненных перипетий, но в то же время еще не открыла закономерностей возникновения гениальности, причин ее избирательности. Это чрезвычайно важно в связи с тем, что число гениев и талантов неуклонно уменьшается. Сама культура в различных ее формах все чаще оказывается в тупиковых ситуациях деградации: мало новых идей и сюжетов, преобладают ремейки, в литературе наблюдается сходство ситуаций в различных произведениях, нет новизны изображения социальных процессов, кроме господства вульгарности и разнузданной брани. Все ниже опускается планка культуры, которая по своей сути в большей мере становится не культурой, а даже антикультурой. Пока нет специалистов, способных вывести культуру из подобного состояния, являть собой способность к высокому уровню изображения истины, добра, красоты, прекрасного.

Изучение причин подобного положения исключительно актуально. Общее падение уровня интеллекта в обществе, отсутствие интереса к познанию, удовлетворение разного рода "развлекаловкой" делают любые исследования по этим вопросам чрезвычайно востребованными, поскольку интеллектуально-духовный регресс приобретает глубину и ширится в своих размерах. Наше изучение жизнедеятельности мыслителя, поэта, естествоиспытателя, государственного деятеля И.В. Гете представляется небезынтересным в плане анализа отношений гения и окружающего сообщества. Привлекают внимание оценки последним его научно-философского образа жизни, реакции различных слоев общества на неординарность позиции И. Гете к своей среде. В связи с этим предпринята попытка исследования романа Т. Манна «Лотта в Веймаре», где автор рассказывает о приезде семидесятидвухлетней Лотты Кестнер (Буфф) в Веймар для встречи с семидесятишестилетним И. Гете [3]. К этому времени он стал первым министром, знаменитым поэтом и писателем, основателем театра, естествоиспытателем, признанным гением. Решение увидеться - более чем смелое для постаревшей женщины. В тексте не идет речь о том, что в глубине души движет нею: тщеславие, интеpec, сожаление по утрате сильного чувства, возможность его реанимации, желание возобновить 
отношения (оба вдовствующие), восстановить интересное общение, сравнение личностных итогов или что-то другое.

В романе уделено много внимания анализу проявлений гениальности И. Гете, его образу жизни, общению и отношениям с близкими, которые не всегда складывались ровно и гармонично.

Еще будучи в гостинице в первые часы пребывания в городе своей юности, Лотта стала объектом пристального внимания многочисленных его обитателей. Долго стоящие на большой площади перед окнами ее номера горожане жаждали лицезреть ту, что стала национальной героиней благодаря шедевру молодого И. Гете «Страдания юного Вертера» [1]. Тут же добиваются встречи с ней несколько знаменитых жителей для засвидетельствования своего почтения, а именно художница, бывший секретарь И. Гете Ф.В. Ример, великосветская дама Адель Шопенгауэр и сын И. Гете Август. Все в своих длительных откровениях с разных сторон и в различных аспектах обрисовывали архисложный для них образ жизни гения, его стиль отношений и позиций. И. Гете предстает в этих рассказах-откровениях очень разным, противоречивым, непредсказуемым. Много сообщалось о прямо противоположных чертах у него, а именно любезности, проявляемой к людям, и в то же время вычурности в общении, частой высокомерности: от отчужденности до холодности.

Все собеседники не лишены высокого уровня ума и просвещенности, понимания значимости творчества И. Гете для мировой культуры. Чаще всего они были неравнодушны в своих откровениях, однако предъявляли высокие требования к гордости нации, нередко останавливали свое внимание на коммуникативных нестыковках, некомфортных социально-психологических нюансировках, неподвластных их пониманию.

Помощник Ример несколько лет прослужил секретарем и переписчиком текстов у И. Гете. По сути он не выдержал постоянного напряжения, исходящего от художественной, эстетической, научной, поэтической одаренности, интеллектуально-философского накала мышления и стиля жизни, задаваемых мэтром. Он ушел на другую, менее интересную, но более спокойную работу. При этом отмечал, что И. Гете создавал приятную рабочую атмосферу, и он часто испытывал счастье быть рядом с ним, черпал удовлетворение от прикосновения к блеску ума гения. Его удивляла способность И. Гете нетривиально выявлять противоречия, видеть их системные проявления в материальных образованиях, совсем не замечаемых другими. Ример скромно называл себя его учеником, считая, что человек обычный вблизи гения должен испытывать восхищение. В то же время он, постоянно сравнивая себя с ним, страдал от занижения собственной самооценки. Он очень тонко и тща- тельно характеризовал обстановку в окружении ученого, но абсолютизировал свои представления о гениальности, силе интеллектуальной мощи. При этом забывал о возможных несовпадениях и постоянно заходил в своем рассказе в тупик при оценке чисто личностных качеств мыслителя.

Адель Шопенгауэр - молодая женщина из великосветского общества, ровесница сына И. Гете Августа, мало непосредственно общавшаяся с И. Гете, в основном повествует о восприятии обществом социального поведения И. Гете, а именно его расположительного отношения к Наполеону, встреч с ним, когда вся Германия горела ненавистью к императору-захватчику. Ее возмущала реакция И. Гете на формирование немецкой армии для борьбы с французской агрессией, «безучастное» и «холодное» его отношение к сыну, сообщала о порицаемой социумом связи мэтра с местной актрисой - матерью Августа. Адель очень изящно характеризует особенности построения И. Гете общения с публикой, резко выступая против не порицаемого и взращиваемого им сервилизма [3, с. 98]. Она не в меньшей степени отрицательно оценивает равнодушие И. Гете к сыну, к его слабому личностному развитию, небрежному обучению, отсутствию у Августа стремления к получению образования, к разгульному образу жизни и пьянству. Адель сообщает, что многие видные деятели культуры страны, в частности И. Гердер, И. Шиллер, Г. Бюргер, Х и Ф. Штольберги, Ф. Клопшток, осуждают адюльтер И. Гете, сетуют на моральную снисходительность к легкомысленному поведению сожительницы. Веймарцы не одобряли препятствия отца вступлению Августа в армию против Наполеона, что очень навредило репутации сына, сделало посмешищем, возвело в ранг труса, помешало установлению светских отношений. Долгое время считаясь внебрачным, он, тем не менее, трогательно относился к обоим родителям: ездил на каменоломни по всей стране за оригинальными образцами минеральных пород для отца, выполнял присутственные поручения, налаживал отношения с поставщиками, принимал посетителей, вел бытовые и хозяйственные дела семьи, проводил работу с разнообразными коллекциями. Август высоко ценил гениальность отца, не признавал негативную позицию общества к его незаконной связи с простой девушкой из народа, чтил память умершей матери.

Сама Лотта Кестнер сохранила в сердце страстную влюбленность в нее юного И. Гете, но в этих разговорах с разной степенью откровенности со своими собеседниками сетовала на те сложности, которые причиняли ухаживания из-за ее статуса невесты Кестнера [2, с. 189, 202, 203]. И. Гете в романе воспроизвел реальную ситуацию, отменно изобразив накал своих любовных чувств. Неоднозначность позиций в глазах общества его 
в то время не занимала. Веселый, изящный, он царил, не задумываясь о положении, в которое ставил, прежде всего, Лотту. Книга заканчивается самоубийством Вертера, а в реальной жизни, получив отказ, И. Гете быстро увлекся новой пассией и забыл о чужой невесте. По словам Лотты, с юности и молодости легкомыслие у И. Гете проявлялось и к служебным обязанностям, и к учебе. Он не утруждал себя изучением наук, но при этом очаровывал остроумием, «жизненным блеском», одухотворенностью, обаянием, умением быть душой компании, интересным собеседником $[2$, с. $185,199,200]$.

Л. Кестнер, разговаривая с Римером, при всем его добром отношении к титану мысли, улавливает у бывшего секретаря некоторую зависть к гетевской самодостаточности, харизме, пассионарности, педалированию уничижающего равнодушия ко многим, странного сочетания «величия духа» и «простоты». Ример также не одобряет безразличие к состоянию образования Августа, «недооценку молодежи и ее внутренней жизни», "обязанностей юношества», попустительство к «понижению градуса ее духовности» и высказывает критичность по поводу социального потенциала немецкой нации [3, с. 58].

При этом необходимо указать, что никто из собеседников Лотты не отметил странную ситуацию, а именно отсутствие отношений между И. Гете и И. Кантом. Прожив одновременно в стране двадцать лет, они не общались [4]. Думается, что невыраженность интереса друг к другу вызвана различными философскими позициями каждого: идеалист И. Кант не мог найти общего языка с материалистом-натуралистом, хотя сам был также представителем естествознания, но на работы И. Канта И. Гете реагировал статьями, отстаивая собственную точку зрения.

И. Гете подчеркивал свою отдаленность от философии, изучая закономерности объективного мира. Однако провозглашаемая философская отчужденность, тем не менее, не помешала ему сделать существенный вклад в мировую науку, создала «эпоху Гете», сформировала величайшую по значимости страницу в истории страны. Важно, что в рассказах собеседников Лотты речь не шла о сущности его открытий и научных достижений.

Сама Лотта родила одиннадцать детей, пятеро из них умерли в младенчестве, остальных она воспитала в благонравии и ответственности перед родителями. Жеенине сложно реагировать на столь неординарные длительные откровения, но она остается на высоте положения, светски сдержанно, любезно и расположительно отвечая на выявленные пассажи.

В реальной действительности встреча героев «Вертера» состоялась на приеме в великолепном доме первого министра. Хозяин был активен, остроумен и велеречив. Гости чаще молчаливо и подобострастно реагировали на его шутки, хихикали над его замечаниями. Душевной атмосферы не получилось. Впечатления о И. Гете у гостьи остались грустными. В письме к взрослому сыну об этой встрече она писала о гордыне, чопорности, напыщенности, церемонности хозяина дома. Он произвел на нее малоприятное впечатление самоупоением. Ей не удалось определить, что им двигало в данной ситуации: мелочность натуры, абсолютизация честолюбия, самовлюбленность, старческий маразм или интеллектуальная деградация. Удивило отсутствие обаяния и легкости в общении [3, с. 288]. Понятно, что в душе ей хотелось увидеть роскошество молодости, изящество движений, подкрепленное умом возраста. Мысленно она «переносилась» в другое время, но осуществить коррекцию не смогла. Сформированный идеал прекрасного не выдержал сравнения с действительностью.

Лотта не концентрирует свое внимание на том, что он автор тринадцати томов по минерологии, тридцать лет работал над текстом философской драмы «Фауст». Кроме того, как государственный деятель первого ранга часто вынужден был бывать в длительных служебных поездках по стране. Он интенсивно занимался развитием Йенского университета, устройством библиотек, школ живописи, обсерватории. Как автор многих поэтических шедевров он был выдающимся поэтом, известным далеко за пределами Германии. Созданный им в Веймаре художественный театр служил задачам просвещения, повышения уровня культуры населения. И. Гете писал для него пьесы, корректировал чужие, издавал книги, в том числе по эстетическим вопросам. Старался не терять творческой и двигательной активности, занимался фехтованием, верховой ездой, физическими упражнениями в уже немолодые годы. Откуда ей было знать, что он автор природоведческих законов, эстетических положений, определений закономерностей культуры, который внес существенный вклад в понимание труда как преобразующей силы общества, деятельностной сущности жизни людей.

Ей подобало бы удивиться тому, сколько успел сделать этот человек, соотнести свой сформированный идеал с итогами его реальной жизни, понять, сколько трудностей ему пришлось преодолеть в борьбе за отстаивание научных идей и принципиальных позиций.

Как говорил А. Эйнштейн, моральные качества выдающихся личностей имеют, возможно, большее значение для данного поколения и всего хода истории, чем чисто интеллектуальные достижения в силу того, что последние мало кому известны, а нравственные проявления доступны широкому кругу обывателей. Прегрешения становятся особенно интересными для всеобщего обсуждения недалеких мещан. 
Люди, не занимающиеся творческой деятельностью, не в состоянии оценить весь размах личностных достижений творца, понять всю силу требуемого напряжения для открытия принципиально нового и снизойти до неудачных коммуникативных его проявлений, испытать снисхождение к нему, позволить быть собой. Они склонны уравнивать побочные особенности как основную характеристику социального потенциала гениальной личности, то есть у всех персонажей романа в итоге много претензий к И. Гете, некое разочарование от того, что он не во всем соответствовал созданному ими бюргерскому идеалу. Безоговорочно, комплексно, как творца мировой культуры на все последующие века, его никто не воспринимал. Они стремились опустить его до обыденности, предъявить претензии, сделать замечания, добавить, если не долю сарказма, то иронии в оценку его «Я». Таким образом, попытка измерить размах интеллектуальных достоинств обывательскими рамками превращается в стремление не только приблизить его к себе, но и уравнять с собой. Все собеседники Л. Кестнер создали в той или иной мере свой филистерский идеал гениальности и всемерно стремились подчеркнуть его несоответствие их представлениям. Они не смогли проявить понимание его коммуникативных сложностей ввиду постоянного изнуряющего умственного труда, перегруженности общественными делами. Лауреат Нобелевской премии по литературе Р. Эйкен (Германия) отмечал, что «интеллектуальное творчество во все времена окружено мелочными интересами, которые быстро и буйно разрастаются, и вовсе не безразлично, оказывается ли этому уродливому разрастанию противоборство» [5, с. 23].

Выводы. Таким образом, сложности отношений и общения представителей науки и философии с ближайшим окружением существенным образом отягощают им жизнь, отнимают силы, предназначенные творчеству.

Автором образ И. Гете обрисован многогранно с опорой на тщательно изученные биографические материалы. Текст читается с большим неослабевающим интересом и вносит много нового в понимание сложностей жизни гения. Т. Манном талантливо изображена иссушающая роль суетности, являющейся существенным тормозом в деятельности талантливого человека.

\section{Лuтература}

1. Гете И.В. Страдания юного Вертера. СанктПетербург : Азбука, 2015. 192 с.

2. Конради О.К. Гете. Жизнь и творчество. Половина жизни. Москва : Радуга, 1987. Т. 1. 592 с.

3. Манн Т. Лотта в Веймаре. Москва : Книга, 1983.302 с.

4. Свасьян К.А. Гете. Новая философская энциклопедия / под. ред. В. Степина. Москва : Мысль, 2010. T. 1. C. $518-522$.
5. Эйкен Р. Натурализм или идеализм? Нобелевская прелия по литературе. Лауреаты 1901-2001 22. Санкт-Петербург : Изд. дом СанктПетербургского университета, 2003. С. 14-24.

6. Эккерман И. Разговоры с Гете в последние годы его жизни. Москва : Художественная литература, $1981.687 \mathrm{c}$.

\section{Анотація}

Лисенкова В. В. Філософські аспекти вивчення способу життя Й. Гете (за романом Т. Манна «Лотта у Веймарі»). - Стаття.

У статті з філософських позицій вивчається специфіка способу життя I. Гете та її бачення мешканцями міста Веймара. У зв'язку з цим зроблена спроба дослідження роману Т. Манна «Лотта у Веймарі».

Цей роман оповідає про приїзд семидесятидвохлітньої Лоти Кестнер (Буфф) у Веймар. Вона є прообразом головної героїні роману I. Гете «Страждання юного Вертера». Якщо головний герой цього твору закінчив життя самогубством у молоді роки, то у реальній дійсності автор роману доріс до генія міжнародного масштабу. Т. Манн тонко і багатогранно відтворює думки різних представників веймарського кола про розмах генія I. Гете, його особистісні якості та роль його творчості у світовому процесі. Однак водночас він розкриває міщанську атмосферу навколо нього, невідповідність його способу життя філістерському ідеалу. У романі приділено багато уваги аналізу проявів геніальності Гете, спілкуванню та відносинам із рідними, які не завжди складались рівно і гармонійно.

Важливість дослідження продиктована тим, що сама культура у різних їі формах все більшою мірою виявляється у безвихідних ситуаціях деградації: мало нових ідей та сюжетів, переважають ремейки, у літературі спостерігається схожість ситуацій у різних творах, мало новизни зображення соціальних процесів, тому осягнення продуктивних основ життєдіяльності геніїв вкрай актуально і перспективно для розвитку усього інтелектуального середовища.

Метою статті є вивчення особливостей способу життя I. Гете та оцінка його діяльності оточенням. Ми бачимо багато чого, а саме нерозуміння складнощів творчого шляху генія, його «внутрішньої лабораторії», поверхове судження про нього з позицій буденного способу життя та справ.

T. Манном образ I. Гете змальований багатогранно з опорою на ретельно вивчені біографічні матеріали. Текст роману читається з великим неослабним інтересом та вносить багато нового у розуміння складнощів життя генію. Письменником талановито зображена звужуюча роль суєтності, яка є істотним гальмом у долі талановитої людини.

Ключові слова: культура, спосіб життя, геній, творча продуктивність, буденність.

\section{Summary}

Lysenkova $V . V$. Philosophical aspects of studying the lifestyle of I. Goethe (based on the novel by T. Mann "Lotta in Weimar"). - Article.

From a philosophical point of view, the article studies the specificity of the lifestyle of I. Goethe and his vision of the inhabitants of the city of Weimar. In this regard, 
an attempt was made to study the novel by T. Mann "Lotta in Weimar".

This novel tells the story of the arrival of the seventy-two-year-old Lotta Kestner (Buff) in Weimar. She is the prototype of the protagonist of Goethe's novel "The Sorrows of Young Werther". If the main character of this work ended his life by suicide in his youth, then in reality the author of the novel has grown into the global genius. T. Mann subtly and multifaceted reproduces the opinions of various representatives of Weimar's society about the scope of Goethe's genius, his personal qualities and the role of his work in the world process. But, at the same time, it reveals the frantic atmosphere around him, the discrepancy between his lifestyle and the philistine ideal. In the novel, much attention is paid to the analysis of the manifestations of Goethe's genius, communication and relationships with loved ones, which did not always develop smoothly and harmoniously.

The importance of the study in the article is dictated by the fact that culture itself in its various forms increasingly finds itself in dead-end situations of degradation: there are few new ideas and plots, remakes prevail, in the literature there is a similarity of situations in various works, there is little novelty in the depiction of social processes. Therefore, the comprehension of the productive foundations of the life of geniuses is extremely relevant and promising for the development of the entire intellectual environment.

The purpose of the article is to study the features of Goethe's lifestyle and the assessment of his activities by the environment. What we have now is in many respects a lack of understanding of the complexities of the creative path of a genius, his "inner laboratory", a superficial judgment about him from the standpoint of an ordinary way of life and occupation.

T. Mann depicted the image of Goethe in many ways, based on carefully studied biographical materials. The text of the novel is read with great unflagging interest and brings a lot of new things into understanding the complexities of the life of a genius. The writer has finely portrayed the draining role of vanity, which is a significant brake on the fate of a talented person.

Key words: culture, lifestyle, genius, creative productivity, everyday life. 